\title{
Long-term analysis of hypothalamic self-stimulation in the rat: Is a circadian rhythm present?
}

\author{
JOHN G. DARK, LOUIS A. CHIODO, and DAVID ASDOURIAN \\ Wayne State University, Detroit, Michigan 48202
}

\begin{abstract}
The course that self-stimulation will take over a long period of time (38 to 82 days) was studied in rats with stimulating electrodes implanted in the lateral hypothalamus. The animals were housed in chambers that allowed continuous access to stimulation. They were maintained on a 12-h light-dark schedule with food and water available ad lib. Analysis showed a definite circadian component in barpressing for intracranial self-stimulation.
\end{abstract}

Of the great number of studies that have been done in the field of intracranial self-stimulation (ICSS), there have been relatively few that involve a longitudinal analysis of continuous opportunity for ICSS. Two early studies, one with monkeys (Lilly, 1958) and one with rats (Olds, 1958), allowed their subjects to barpress for ICSS $24 \mathrm{~h}$ a day for several days. In both cases, the animals were reported to self-stimulate until they slept due to exhaustion; however, in neither case was an analysis made to determine the presence or absence of a circadian rhythm.

Unpublished observations made in this laboratory have indicated that rats would barpress continuously for up to $24 \mathrm{~h}$ if electrodes were implanted within the lateral hypothalamus. This suggested that this behavior may override the normal entrainment of activity to the light-dark (LD) cycle.

Although more recent long-term studies (Terman \& Terman, 1970; Valenstein \& Beer, 1964) have reported evidence that suggests that barpressing for ICSS may occur in a circadian rhythm, both studies were run in continuous illumination rather than a controlled LD cycle. It remains unknown at this time, therefore, whether or not a daily rhythm of ICSS occurs in synchrony with cyclic illumination, as do such other motivated behaviors as eating and drinking (Richter, 1965; Rusak \& Zucker, 1975), or if there is only a repeating cycle of barpressing and exhaustion.

Terman and Terman (1970) also reported that self-stimulation does not show a discrete onset as does locomotor activity, but occurs as a continuous stream with cyclic oscillations in rate of responding.

The authors wish to thank Dr. Carol M. Christensen for her technical assistance and Judy Reese for her work on the manuscript. Requests for reprints should be sent to John G. Dark, 400 Old Main, Wayne State University, Detroit, Michigan 48202 .
However, this may be due to their oscillations being cycles of exhaustion and recovery, not true circadian rhythms. Also, if there is a circadian rhythm of ICSS, it can be argued that their results may be due to Terman and Terman's use of constant light. Selfstimulation may show a discrete onset, as does activity, when the animals are exposed to cyclic environmental illumination.

The twofold purpose of the present study is to observe the daily pattern lateral hypothalamic ICSS will take (especially at the onset and offset of illumination) when an animal is allowed continuous access to ICSS for long periods of time in a controlled LD cycle and to look at daily barpressing for a change in rate; that is, do animals continue pressing indefinitely at a relatively stable rate or are there systematic changes in responding across time?

\section{METHOD}

\section{Subjects}

Five female Sprague-Dawley albino rats weighing from 275 to $325 \mathrm{~g}$ at the time of electrode implantation were used.

\footnotetext{
Apparatus

The apparatus consisted of two self-stimulation chambers, $30 \times 30 \times 60 \mathrm{~cm}$, equipped with a commutator that allowed the animals freedom of movement through rotation of the connecting cable.

Each barpress provided a subject with intracranial stimulation which consisted of a 150 -msec pulse of 60 -cycle current. The value of the current varied from 50 to $200 \mu \mathrm{A}$ depending upon the animal's response to stimulation. Every barpress was recorded on a counter and every third barpress on an Esterline-Angus Operation Recorder (Model AW, Style 90M).

Procedure

Bipolar electrode implantation was performed while the animals were anesthetized with sodium pentobarbitol $(6 \mathrm{mg} / 100 \mathrm{~g}$ body weight). They were also given atropine sulfate $(0.2 \mathrm{cc})$ to help prevent postoperative congestion. The electrode was composed to two twisted strands of $0.25-\mathrm{mm}$ stainless steel wire (Plastic Products Co.). Electrode implantation was made with the incisor bar $5 \mathrm{~mm}$ above the interaural line at these coor-
} 

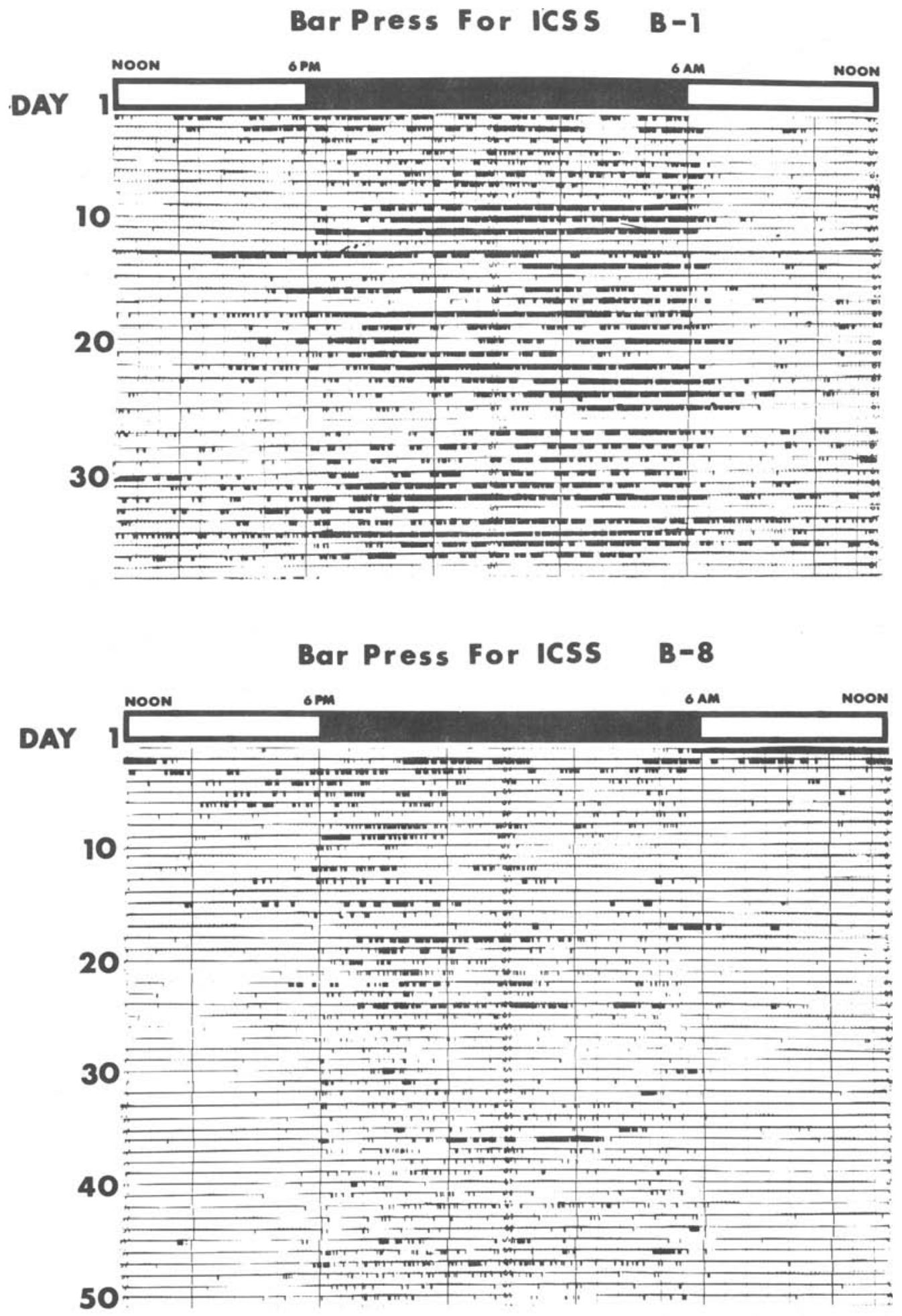

Figure 1. The strip charts of animals B-1 and B-8 which display barpressing across time. Each deflection of the pen represents three barpresses.

dinates: $0.2 \mathrm{~mm}$ anterior to bregma, $2.0 \mathrm{~mm}$ lateral to bregma, and $7.0 \mathrm{~mm}$ ventral to dura.

A minimum period of $48 \mathrm{~h}$ was allowed for recovery following surgery before shaping was attempted. The animals were trained to barpress for ICSS on a continuous reinforcement schedule.
Once an animal had acquired self-stimulation, it was left in the chamber $24 \mathrm{~h}$ a day with continuous opportunity to barpress. Food and water was available ad lib. The experimental room was illuminated by five $40-\mathrm{W}$ fluorescent lamps that automatically came on at 6:00 a.m. and went off at 6:00 p.m. 
The shortest continuous period an animal was left in the selfstimulation chamber was 38 days, and the longest, 82 days. To perform a histological examination to confirm electrode placement, the animals were sacrificed and perfused first with $0.9 \%$ saline, and then with $10 \%$ Formalin. Frontal sections, cut every $75 \mu$ in the area of the electrode track, were stained with cresyl violet and examined under a light microscope using Pellegrino and Cushman's (1967) atlas of the rat brain as a reference.

\section{RESULTS}

Figure 1 shows the strip charts for two of the animals. The charts show when self-stimulation occurred as a function of time of day. These charts reveal that the animals exhibited a circadian component in their daily self-stimulation. The greatest frequency barpressing for ICSS can be seen to have occurred during the dark period. Most of the animals showed a discrete onset of barpressing behavior and a discrete offset of behavior was observed in all of the animals.

The increased likelihood of self-stimulation occurring during the dark period and the distinct offset of behavior becomes apparent in Figure 2. Each bar of the histograms indicates that the number of days on which an animal barpressed (at least once) during that 1 -h period.

A statistical comparison of the average frequency of days on which ICSS occurred for the light hours vs. the dark hours was made for each animal. The average frequency of ICSS during the dark period
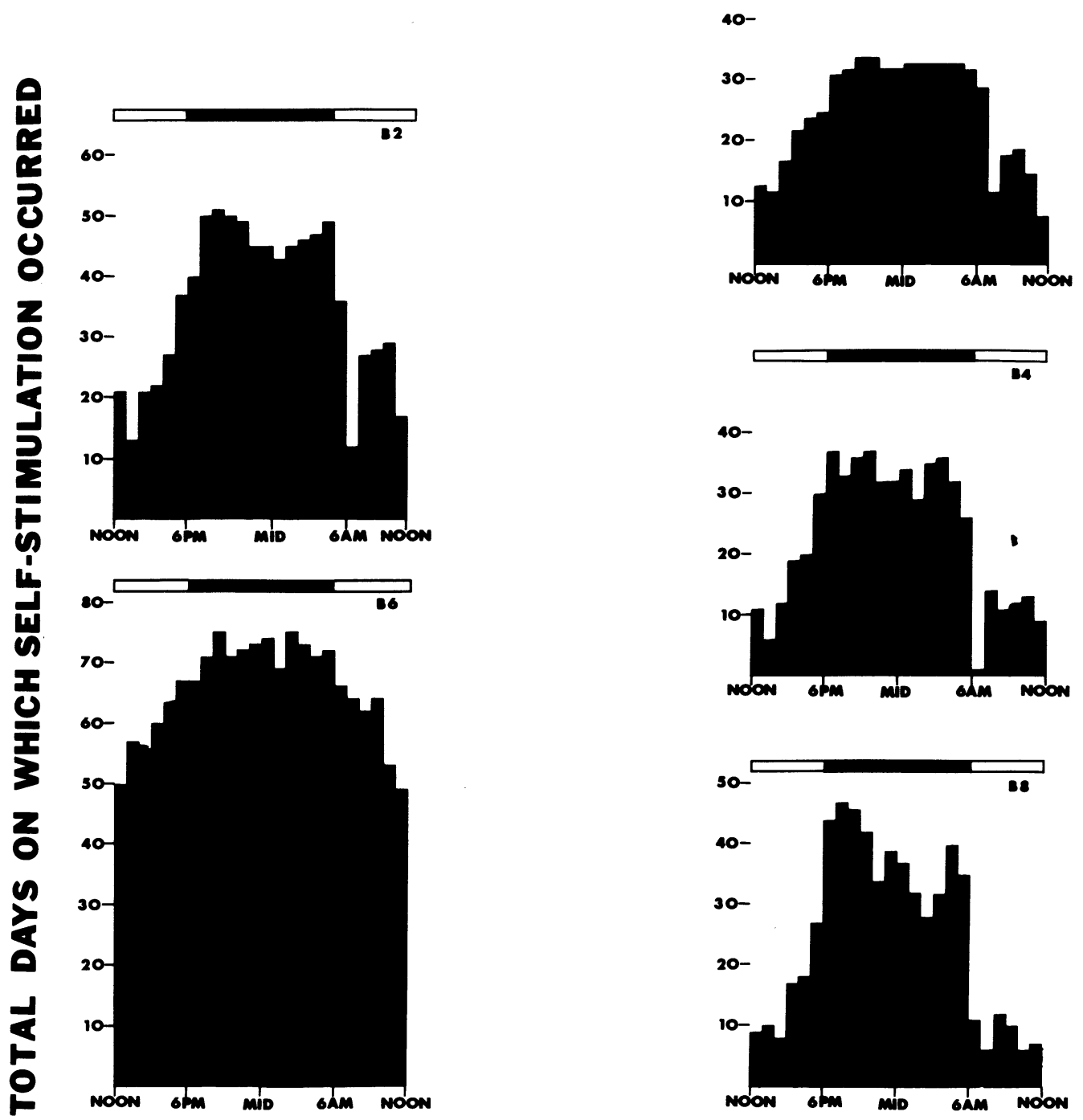

\section{EACH DAY IN ONE HOUR PERIODS}

Figure 2. Histograms showing the total number of days on which self-stimulation occurred (at least once) for each 1-h period of the day. The dark period extended from 6 p.m. to 6 a.m. 


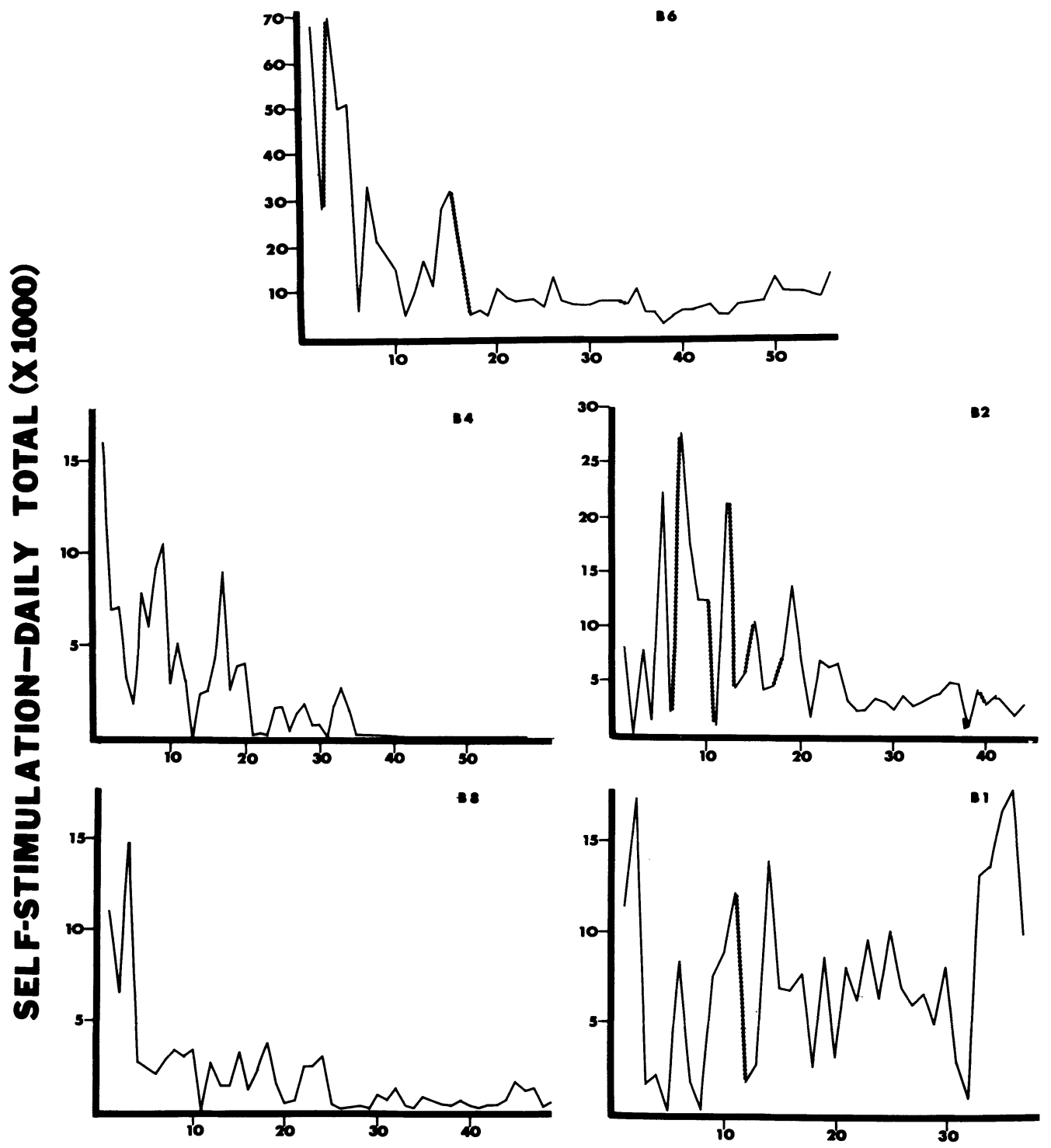

DAYS

Figure 3. Graphical representations of the total number of barpresses made daily for ICSS by each animal. Dotted lines indicate a loss of data due to equipment failure.

was significantly greater than during the light period for all five animals ( $t$ test, $p<.001$ ).

Representations of the total daily ICSS for each animal are depicted in Figure 3. Examination of Figure 3 shows no apparent day-to-day rhythm of any kind. Although there is no evidence of a day-today rhythm, the graphs in Figure 3 do reveal that all of the animals but one (B-1) showed an initial high rate of barpressing with a gradual decline thereafter.

Examination of the histological preparations verified that in each case the electrode tip was situated within the lateral hypothalamus or the medial fore- brain bundle. The histology of all of the animals but one (B-6) showed tissue surrounding the tip to display some signs of damage, which may have been a result of current.

\section{DISCUSSION}

This experiment shows that there is a definite circadian component in the daily barpressing a rat makes for lateral hypothalamic ICSS under a controlled LD schedule over long periods of time. This circadian component is apparent in both the records of barpressing across time and in a comparison of 
Table 1

Comparison of Light and Dark Hourly Averages of Number of Days During Which Barpressing Occurred at Least Once

\begin{tabular}{ccccccc} 
& \multicolumn{2}{c}{ Light } & & \multicolumn{2}{c}{ Dark } & \\
\cline { 2 - 3 } Animal & Mean & SD & & Mean & SD & $\mathrm{p}<$ \\
\hline B-1 & 17.83 & 6.25 & & 32.83 & 1.03 & .001 \\
B-2 & 24.17 & 8.02 & & 46.67 & 3.20 & .001 \\
B-4 & 13.17 & 7.35 & & 33.25 & 3.33 & .001 \\
B-6 & 59.25 & 6.17 & & 71.92 & 2.35 & .001 \\
B-8 & 11.67 & 6.18 & & 38.00 & 6.03 & .001 \\
\hline
\end{tabular}

likelihood to respond during the light period vs. the dark period. This finding extends earlier studies using constant light. Also, it is consistent with the fact that there is evidence of a relationship between lateral hypothalamic ICSS and feeding (Hoebel \& Teitelbaum, 1962) and that feeding is seen to occur in a circadian rhythm (Richter, 1965; Rusak \& Zucker, 1975). Interestingly, it has been found that the lateral hypothalamus receives neural input from the suprachiasmatic nucleus of the hypothalamus (Swanson \& Cowan, 1975), which has recently been shown to be responsible for the rat's circadian rhythms of activity and drinking (Stephan \& Zucker, 1972).

Unlike Terman and Terman (1970), our study found that most of our animals showed an onset of barpressing as discrete as that observed in this laboratory for locomotor activity under the same conditions (Dark \& Asdourian, 1975). In addition, all of the animals exhibited a distinct offset of behavior corresponding to the onset of the light period.

There was an absence of any kind of day-to-day rhythm or systematic pattern of daily barpressing totals other than an initially higher rate of barpressing followed by a very general decrease in rate that is observed in all but one of the animals. Valenstein and Beer's (1964) graph of total daily barpressing across time for their single animal reveals a similar general decrease in daily barpressing rate. Four of the five animals showed apparent tissue damage around the tip of the electrode, but the one animal that appeared to lack damaged tissue was not the same animal that failed to show the general decline in response rate. There does not appear to be any correspondence, then, between tissue damage and response rate; however, this can not be unequivocally ruled out.

We have shown than when studied continuously over long periods of time, ad-lib ICSS at lateral hypothalamic sites contains a definite circadian component; this is consistent with other motivated behaviors, such as eating and drinking, which have been shown to be circadian in nature (Richter, 1965; Rusak \& Zucker, 1975).

\section{REFERENCES}

DARK, J. G., \& AsDourian, D. Entrainment of the rat's activity rhythm by cyclic light following lateral geniculate nucleus lesions. Physiology \& Behavior, 1975, 15, 295-301.

Hoebel, B. G., \& Teitelbaum, P. Hypothalamic control of feeding and self-stimulation. Science, 1962, 135, 375-377.

LILLY, J. L. Learning motivated by subcortical stimulation: The start and stop patterns of behavior. In H. H. Jasper, L. D. Procter, R. S. Knighton, W. C. Noshay, \& R. T. Costello (Eds.), The reticular formation of the brain. Boston: Little Brown, 1958.

OLDs, J. Satiation effects in self-stimulation of the brain. Journal of Comparative and Physiological Psychology, 1958, 51, 675-678.

Pellegrino, L. J., \& Cushman, A. J. A stereotaxic atlas of the rat brain. New York: Appleton-Century-Crofts, 1967.

RICHTER, C. P. Biological clocks in medicine and psychiatry. Springfield, Ill: Thomas, 1965.

RuSAK, B., \& ZuCKER, I. Biological rhythms and animal behavior. Annual Review of Psychology, 1975, 26, 137-171.

Stephan, F. K., \& Zucker, I. Circadian rhythms in drinking behavior and locomotor activity of rats are eliminated by hypothalamic lesions. Proceedings of the National Academy of Sciences, U.S.A., 1972, 69, 1583-1586.

Swanson, L. W., \& Cowan, W. M. The efferent connections of the superchiasmatic nucleus of the hypothalamus. Journal of Comparative Neurology, 1975, 160, 1-12.

Terman, M., \& Terman, J. S. Circadian rhythm of brain selfstimulation behavior. Science, 1970, 168, 1242-1244.

Valenstein, E. S., \& BeER, B. Continuous opportunity for reinforcing brain stimulation. Journal of the Experimental Analysis of Behavior, 1964, 7, 183-184.

(Received for publication August 16, 1976; revision accepted November $19,1976$. 